\title{
Enzymatic Flow Injection Method for Rapid Determination of Choline in Urine with Electrochemiluminescence Detection
}

\author{
Jiye Jin*, Masahiro Muroga, Fumiki Takahashi and Toshio Nakamura \\ Faculty of Science, Shinshu University, 3-1-1 Asahi, Matsumoto, \\ Nagano 390-8621, Japan
}

\begin{abstract}
In order to determine trace choline in human urine, a flow injection analysis (FIA) system has been developed by coupling of an enzyme reactor with an electrochemiluminescence (ECL) detector. The enzyme reactor is prepared by covalently immobilizing of choline oxidase ( $\mathrm{ChOx}$ ) onto the aminopropyl-controlled pore glass beads, which are then carefully packed into a micro column. The enzyme reactor catalyzes the production of hydrogen peroxide that is in direct proportion to the concentration of choline. In this study, the enzymatically produced hydrogen peroxide was detected by an ECL detector positioned at the down stream of enzyme reactor based on the luminol/ $\mathrm{H}_{2} \mathrm{O}_{2}$ ECL system. Under the optimized condition, the enzymatic FIA/ECL provided high sensitivity for the determination of choline with the detection limit as low as $0.05 \mu \mathrm{M}$ (absolute detection limit was at sub pmol level). The method was successfully applied in the determination of choline in the samples of human urine, and the analytical results were in good agreement with those obtained by using the microbore HPLC with immobilized enzyme reactor-electrochemical detection system.
\end{abstract}

Keywords: Electrochemiluminescence; Flow injection; Enzyme reactor; Choline; Human urine.

\footnotetext{
* Corresponding author. Tel\&Fax: +81-263372475; E-mail: jin@ shinshu-u.ac.jp
} 


\section{Induction}

Choline is classified as a water soluble essential nutrient which plays a vital role in maintaining the central nervous system and numerous metabolic functions. For example, it is a precursor of membrane and lipoprotein phospholipids and the neurotransmitter acetylcholine; and thus is important for the integrity of cell membranes, lipid metabolism, and cholinergic nerve function $[1,2]$. The development a sensitive and rapid method for the determination of choline in biological fluids, such as plasma and urine, has become an important subject in the fields of biochemistry because it would certainly aid in studying the metabolism of this physiologically important substance [3, 4]. Till now, there has been rare paper concerned with the development of a suitable method for the determination of free choline in the human urine.

Choline is neither UV-absorbing nor electroactive. However, via an enzymatic reaction with choline oxidase $(\mathrm{ChOx})$, choline is oxidized to betaine with the simultaneous production of hydrogen peroxide $\left(\mathrm{H}_{2} \mathrm{O}_{2}\right)$, which can be easily detected by amperometric and photometric methods [5-10]. In particular, choline in biochemical and clinical applications is determined by HPLC separation techniques in many clinical laboratories [11-14]. Although these techniques provide high sensitivity, they are tedious and time-consuming. Compared with the HPLC separation techniques, flow injection analysis (FIA) offers many significant advantages such as rapidity, higher precision along with the cost-effectiveness. Nevertheless, the common biosensors suffer from the problem of poor stability caused by loss of enzyme from the sensing layer of electrode especially when were used in flow analysis detection systems. To improve the stability as well as the sensitivity, an immobilized enzyme reactors coupled with 
amperometric has been described for choline determination since the enzyme reactor offer the advantages of higher substrate conversion efficiency and long-lived activity [15]. $\mathrm{H}_{2} \mathrm{O}_{2}$ released from the reactor can be detected with to a suitable detector placed in the downstream. Because the detection potentials for $\mathrm{H}_{2} \mathrm{O}_{2}$ were usually high $(+0.7$ +0.9 V vs. SCE) at a Pt electrode [16], many substances such as ascorbic acid or uric acid in biological fluids can interfere with the measurements without the separation procedures. In order to rejecting the electroactive interferences, an alternative approach was proposed by use of Pt electrode modified with the electrosynthesized polymeric membrane [15].

Electrochemiluminescence or electrogenerated chemiluminescence (ECL) is a kind of luminescence produced during electrochemical reactions in solutions [17]. Since ECL of luminol can be initiated by applying an appropriate positive potential to the working electrode in the presence of $\mathrm{H}_{2} \mathrm{O}_{2}$, the biosensors constructed with $\mathrm{H}_{2} \mathrm{O}_{2}$ producing enzymes could be measured by ECL principle. In previous study, Blum et al. successfully developed a various ECL biosensors using screen-printed electrodes and multifunctional biosensing chip [18-20]. It was shown that ECL measurements enable the achievement of high sensitive methods, free of the matrix interference, for the detection of glucose, lactate, choline and glutamate. The present study describes the application of enzyme reactor coupled with an ECL detector for rapid and sensitive determination of choline in a FIA system. The enzyme reactor used in this study was made from the aminopropyl-controlled pore glass (ACPG) beads on which ChOx was bonded by covalent reaction. It is converted to betaine with simultaneous formation of $\mathrm{H}_{2} \mathrm{O}_{2}$ by enzyme catalyzed reaction in the reactor, and the produced $\mathrm{H}_{2} \mathrm{O}_{2}$ is subsequently detected in an ECL flow cell positioned at the downstream of the reactor. 
The method was shown to be sufficiently sensitive to determine the trace choline in human urine, and the analytical results were in good agreement with the data by HPLC.

\section{Experimental}

\subsection{Chemicals}

3-Aminophthaloylhydrazine (luminol), $50 \%$ choline chloride solution, choline oxidase (ChOx) (from alcaligenes species) were purchased from Wako Pure Chemical Industries, Ltd (Osaka, Japan). All other chemicals used in the present study were of analytical grade. Sample solutions were prepared by diluting the required amount of stock solution with $0.1 \mathrm{M}$ phosphate buffer (PBS) before use. The $\mathrm{pH}$ of PBS was adjusted to a desired $\mathrm{pH}$ value with sodium hydroxide.

\subsection{Preparation of the enzyme immobilized reactor}

ChOx was covalently immobilized on ACPG beads (Sigma) by crosslinking with glutaraldehyde according to the scheme in Fig.1a. First, the ACPG beads (200 mg) were gently stirred in $2 \mathrm{~mL}, 2.5 \%$ glutaraldehyde solution for 90 minutes at room temperature. The glutaraldehyde-treated ACPG beads were washed with $0.1 \mathrm{M} \mathrm{PBS}(\mathrm{pH}$ 8.0), and then transferred into $2 \mathrm{~mL} 0.1 \mathrm{M}$ PBS containing about 100 units of ChOx. After the reaction for 24 hour at $4{ }^{\circ} \mathrm{C}$, the enzyme-immobilized beads were rinsed with 0.1 M PBS, and then carefully packed into a reactor-column, with 2-mm in diameter and $10-\mathrm{mm}$ in length. The construction of the reactor to be used in this experiment is schematically shown in Fig. 1b. The reactor was stored at $4{ }^{\circ} \mathrm{C}$ when it was not in use.

Here Fig. 1 


\subsection{Apparatus and procedures}

The flow injection apparatus of a Shimadzu LC-10-ATVT serial dual plunger pump, a six-port Rheodyne injector valve fitted with a 10- $\mu \mathrm{L}$ sample loop, and an ECL flow cell. The ECL cell was reconstructed from a commercial electrochemical flow cell (BAS Japan) with three-electrode set up. The working electrode was 6-mm diameter glassy carbon electrode shrouded in a PEEK block. The stainless steel tube outlet and $\mathrm{Ag} / \mathrm{AgCl}$ electrode (RE-3V, BAS Japan) were used as counter electrode and reference electrode, respectively. In the flow cell, an optic fiber with core size of $1 \mathrm{~mm}$ was installed opposite to the surface of working electrode, as is shown in Fig.2. The light emission from the electrode surface was captured through the optic fiber using a H7468-01 photomultiplier tube (PMT) module (Hamamatsu Photonics, Japan), which was controlled by a notebook computer using a laboratory-written software package via RS-232C interface. Cyclic voltammetry and the potential control in ECL were performed with a model 800 electrochemical workstation $(\mathrm{CH}$ Instruments, Austin, TX, USA). The enzyme reactor was connected prior to the ECL flow cell. $0.1 \mathrm{M} \mathrm{PBS}$ (pH 8.5) containing $50 \mu \mathrm{M}$ luminol was used as a carrier solution. The ECL-potential curves were measured with a micro ECL cell as we previously reported [21]. A silver wire was employed as quasi-reference electrode (Ag QRE) in the measurement. HPLC determinations were conducted with a semi-micro LC system using a LC-50 pump (BAS) and a Sepstick ${ }^{\mathrm{TM}}$ microbore column $(150 \times 1 \mathrm{~mm}, 5 \mu \mathrm{m} \mathrm{C18}$; BAS). The ChOx immobilized reactor was connected to the outlet of the analytical column. The enzymatically produced $\mathrm{H}_{2} \mathrm{O}_{2}$ was amperometric detected by an electrochemical detector at a platinum electrode. A detection potential of $+0.65 \mathrm{~V}$ vs. $\mathrm{Ag} / \mathrm{AgCl}$ was used. 
All measurements were conducted at room temperature $\left(22-23{ }^{0} \mathrm{C}\right)$.

Here Fig. 2

\subsection{Preparation of urine samples}

Human urine samples were obtained from healthy volunteers in the laboratory. The urine was first diluted 1:10 in PBS $(\mathrm{pH}=8.5)$, and was transferred into a centrifugal filtrating tube $(0.22-\mu \mathrm{m}$ pore size micro porous membrane, Ultrafree-MC, Millipore). After being centrifuged for $5 \mathrm{~min}$ at $3000 \mathrm{~g}$, the filtrate was further passed through a glass column with $80 \mathrm{~mm}$ in length and $6 \mathrm{~mm}$ in diameter in which the Dowex 1 anion-exchange resin was packed, to remove the interference, such as ascorbic acid. The filtrate was injected into the FIA system. To determine the recovery, amount of choline was spiked into the same sample prior to dilution.

\section{Results and discussion}

The ECL behavior of the luminol/ $\mathrm{H}_{2} \mathrm{O}_{2}$ system was evaluated by cyclic voltammetry at a GC electrode. Figure 3a shows the cyclic voltammograms of $50 \mu \mathrm{M}$ luminol (dashed line) and $50 \mu \mathrm{M}$ luminol $+\mathrm{H}_{2} \mathrm{O}_{2}$ (solid line) in 0.1 M PBS ( $\mathrm{pH}=8.5$ ), respectively. The corresponding ECL intensity $\left(I_{\mathrm{ecl}}\right)$ - potential profiles during the potential scan are shown in Fig.3b. The light emission was observed when the potential was scanned from 0 to $+0.8 \mathrm{~V}$, being the maximum at ca. $+0.6 \mathrm{~V}$ vs. Ag QRE. ECL of luminol has been studied intensively and the light emission was thought to result from the oxidation of luminol to a radical, which reacts with a superoxide radical to form 3-aminophthalate in an excited state [21]. 
Here Fig. 3

The effect of $\mathrm{pH}$ on the ECL intensity of luminol/ $/ \mathrm{H}_{2} \mathrm{O}_{2}$ system was investigated over the $\mathrm{pH}$ range from 7.0 to 11.0. As can be seen in Fig.4a, the strongest ECL signal was observed around $\mathrm{pH} 9-10$. On the other hand, the luminol ECL background ( $\left.I_{\text {ecl,background }}\right)$ was also increased with increasing of the $\mathrm{pH}$ value, and $I_{\text {ecl,background }}$ became considerable large when the $\mathrm{pH}$ was above 11.0 (Fig.4b). Figure $4 \mathrm{c}$ shows a plot of the normalized ECL intensity $\left(I_{\mathrm{ecl}, \mathrm{N}}\right)$ as function of $\mathrm{pH}$ value. Here, $I_{\mathrm{ecl}, \mathrm{N}}$ is defined as the ECL intensity ratio of signal to background $\left(I_{\mathrm{ecl}, \mathrm{N}}=I_{\mathrm{ecl}} / I_{\mathrm{ecl}, \text { background }}\right)$. Since $I_{\mathrm{ecl}, \mathrm{N}}$ reached maximum value around $\mathrm{pH} 8-9$, the $\mathrm{pH}$ range was suggested to be the optimum condition for $\mathrm{H}_{2} \mathrm{O}_{2}$ detection. At $\mathrm{pH} 8.5, \mathrm{I}_{\text {ecl }}$ was proportional to the concentration of $\mathrm{H}_{2} \mathrm{O}_{2}$ in a range from 0 to $10.0 \mu \mathrm{M}$ with a correlation coefficient of 0.998 . Determining of an optimum $\mathrm{pH}$ in enzymatic FIA system is important because $\mathrm{pH}$ for ECL detection should match with that for $\mathrm{ChOx}$ enzymatic reaction. It has been reported that $\mathrm{ChOx}$ works best in a $\mathrm{pH}$ range from 8 - 8.5 [22]. In this study, the effect of $\mathrm{pH}$ on the enzyme activity of the immobilized ChOx was examined by injection $10 \mu \mathrm{M}$ choline in FIA system using a ChOx reactor. The enzymatically produced $\mathrm{H}_{2} \mathrm{O}_{2}$ was amperometrically detected on a platinum electrode at $+0.65 \mathrm{~V}$ vs. $\mathrm{Ag} / \mathrm{AgCl}$. The experiment results confirmed that the immobilized $\mathrm{ChOx}$ gave the best enzymatic activity around $\mathrm{pH}$ 8.5. Since the $\mathrm{pH}$ value was favorable to both ECL detection and the enzymatic reaction, it was thus chosen as carrier solution in the subsequent experiments.

Here Fig.4 
As expected, a marked ECL signal was observed when choline sample was injected in the enzymatic FIA system. Choline was first catalytically oxidized by $\mathrm{ChOx}$ and immediately converted into betaine and $\mathrm{H}_{2} \mathrm{O}_{2}$ in the reactor. The produced $\mathrm{H}_{2} \mathrm{O}_{2}$ was then detected in the ECL flow cell according to the following reactions [22].

$$
\begin{aligned}
& \text { Choline }+\mathrm{O}_{2}+\mathrm{H}_{2} \mathrm{O} \stackrel{\text { hox }}{\rightarrow} \text { betaine }+2 \mathrm{H}_{2} \mathrm{O}_{2} \quad \text { (enzyme reactor) } \\
& \text { Luminol }+\mathrm{H}_{2} \mathrm{O}_{2} \rightarrow \text { light }(425 \mathrm{~nm})(\text { ECL flow cell, } \mathrm{E}=+0.8 \mathrm{~V})
\end{aligned}
$$

ECL intensity is directly proportional to $\mathrm{H}_{2} \mathrm{O}_{2}$ concentration, and therefore to choline concentration. The signal intensity was found to be dependent on the flow rate of carrier solution. It increased gradually from 0.2 to $1.0 \mathrm{~mL} / \mathrm{min}$, and decreases slowly above $1.0 \mathrm{~mL} / \mathrm{min}$. The increased ECL signal was due to the increase of mass transport of luminol and $\mathrm{H}_{2} \mathrm{O}_{2}$ in electrode process. However, when the flow rate was increased greater than $1.0 \mathrm{ml} / \mathrm{min}$, the ECL signal was decreased. This may be a consequence of decreasing of the enzymatic reaction time in the reactor, and the produced $\mathrm{H}_{2} \mathrm{O}_{2}$ became less accordingly. In this work, an optimum flow rate of $1.0 \mathrm{~mL} / \mathrm{min}$ was used.

The concentrations of luminol in mobile phase also affected the ECL detection in FIA. The higher concentration of luminol would result higher ECL intensity, but it will accompany by an increase in the background signal level, and will affect the reproducibility of ECL analytical signal as well. The concentration of luminol was optimized to be $50 \mu \mathrm{M}$, which achieved the best signal to noise $(\mathrm{S} / \mathrm{N})$ ratio in the detection of $\mathrm{H}_{2} \mathrm{O}_{2}$. The $\mathrm{S} / \mathrm{N}$ ratio was also depended on the detection potential. It was 
observed that the light intensity increased with increasing the potential from +0.4 to $+1.0 \mathrm{~V}$ vs. $\mathrm{Ag} / \mathrm{AgCl}$, but the $\mathrm{S} / \mathrm{N}$ ratio reached a maximum at a potential of $+0.8 \mathrm{~V}$ vs. $\mathrm{Ag} / \mathrm{AgCl}$. Therefore, a detection potential of $+0.8 \mathrm{~V}$ vs. $\mathrm{Ag} / \mathrm{AgCl}$ was employed for all subsequent experiments.

Figure 5 shows the typical FIA responses to various concentrations of choline at an applied potential of $+0.8 \mathrm{~V}$ vs. $\mathrm{Ag} / \mathrm{AgCl}$ in FIA system. A good operation range between 0 to $2.0 \mu \mathrm{M}$ with the correlation coefficient being 0.998 , was adjusted for this system. The relative standard deviations $(\mathrm{n}=5)$ were about $2-3 \%$. The detection limit of 0.05 $\mu \mathrm{M}$ (absolute detection limit: $0.5 \mathrm{pmol}$ ) was achieved as an estimated based on $\mathrm{S} / \mathrm{N}>3$. This value is much lower than those obtained by the electrochemical biosensors as we previously reported [7]. Notably, the enzyme reactor exhibited much good stability than the enzyme immobilized biosensors. In general, the enzyme reactor maintained its activity over 3 months with the signal variation less than $\pm 8 \%$ if the reactor was preserved carefully to eliminate the growth of bacteria (known to be efficient scavengers of $\mathrm{H}_{2} \mathrm{O}_{2}$ ) and stored at $4{ }^{\circ} \mathrm{C}$ when not in use.

Here Fig.5

Ascorbic acid and uric acid are usually present in biological fluids which interfere to electrochemical measurements especially in the amperometric detections $[23,24]$. It was found that coexisted ascorbic acid or uric acid would suppress the ECL signal in certain level because these reducing species can act as a scavenger of superoxide radical, and quenched the light intensity in luminol / $\mathrm{H}_{2} \mathrm{O}_{2}$ ECL system [25]. Since choline is a cation while ascorbic acid is an anion at the employed $\mathrm{pH}$ condition, these interferences 
were easily eliminated by passing $1.0 \mathrm{~mL}$ of sample through an anion exchange column (a glass tube with $80 \mathrm{~mm}$ in length and $6 \mathrm{~mm}$ in diameter in which DOWEX 8-2X anion-exchange resin was packed). When a sample of $1.0 \mu \mathrm{M}$ choline was spiked with $1000.0 \mu \mathrm{M}$ of ascorbic acid (or uric acid), the FIA analytical signal was confirmed to be consistent with the sample of ascorbic acid (or uric acid) free after the separation procedure, indicating that ascorbic acid could be effectively removed by the anion exchange procedure.

Table 1 shows the results for the determination of choline in human urine by the proposed method. The urine samples were first diluted 1:10 with PBS $(\mathrm{pH}=8.5)$, and then passed through the anion exchange column. To determine the recovery of the method, amount of choline as internal standard was spiked into the samples before dilution. It can be seen that this method provided good recovery of choline in urine samples. The quantitative results were compared with the analytical data determined by microbore HPLC using immobilized enzyme reactor and electrochemical detection method [12], as recommended by Bioanalytical System Inc. Good agreement was achieved. The advantages of versatility, sensitivity, and simple instrumentation make this method to be possible in routine analysis of choline in biochemical samples.

\section{Here Table 1}

\section{Conclusions}

In conclusion, flow injection analysis of trace choline in human urine with ChOx-immobilized enzyme reactor coupled to the ECL detection was developed in this study. The results demonstrated that ECL detection provided improved selectivity, 
stability and detection limit in comparison with the conventional method. The method was successfully applied in the determination of trace choline in the samples of human urine with good recovery. The most important advantages of the proposed method over the HPLC for urinary choline are its high sensitivity, simplicity and speedy.

\section{Acknowledgement}

The authors gratefully acknowledge the Matsuko Science and Technology Foundation for the financial support. 


\section{References}

[1] L. M. Sanders, S. H. Zeisel, Choline: Dietary requirements and role in brain development, Nutr Today, 42, (2007)181-186

[2] S.H. Zeisel, K.D. Costa, P. D. Franklin, E.A. Alexander, J.T. Lamont, N.F. Sheard, A. Beiser, Choline, an essential nutrient for humans, The FASEB Journal, 5, (1991)2093-2098.

[3] N.F. Sheard, J.A. Tayek, B.R. Bistrian, G.L. Blackburn, S.H. Zeisel, Plasma choline concentration in humans fed parenterally, Am. J. Clin. Nutr., 43, (1986) 219-224.

[4] F. Dieterle, G. Schlotterbeck, A. Ross, U. Niederhauser, H. Senn, Application of metabonomics in a compound ranking study in early drug development revealing drug-induced excretion of choline into urine, Chem. Res. Toxicol., 19, (2006) $1175-1181$.

[5] Y.-H. Bai, Y. Du, J.-J. Xu, H.-Y. Chen, Choline biosensors based on a bi-electrocatalytic property of $\mathrm{MnO}_{2}$ nanoparticles modified electrodes to $\mathrm{H}_{2} \mathrm{O}_{2}$, Electrochem. Comm., 9, (2007)2611-2616.

[6] M. Yang, Y. Yang, Y. Yang, G. Shen, R. Yu , Bienzymatic amperometric biosensor for choline based on mediator thionine in situ electropolymerized within a carbon paste electrode, Anal. Biochem., 334, (2004)127-134.

[7] Z. Song, J.-D. Huang, B.-Y. Wu, H.-B. Shi, J.-I. Anzai, Q. Chen, Amperometric aqueous sol-gel biosensor for low-potential stable choline detection at multi-wall carbon nanotube modified platinum electrode, Sens. Actuators B, 115, 
(2006)626-633.

[8] F. Qu, M. Yang, J. Jiang, G. Shen, R. Yu, Amperometric biosensor for choline based on layer-by-layer assembled functionalized carbon nanotube and polyaniline multilayer film, Anal. Biochem., 344, (2005)108-114.

[9] Minghui Yang, Yunhui Yang, Yu Yang, Guoli Shen, Ruqin Yu, Microbiosensor for acetylcholine and choline based on electropolymerization/sol-gel derived composite membrane, Anal. Chim. Acta, 530, (2005)205-211.

[10] Javier Galbán, O. Sánchez-Monreal, Y. Andreu, S. de Marcos, J. R. Castillo, Choline determination based on the intrinsic and the extrinsic (chemically modified) fluorescence of choline oxidase, Anal. Biochem., 334, (2004)207-215.

[11] R. Maeba, N. Ueta, Determination of choline and ethanolamine plasmalogens in human plasma by HPLC using radioactive triiodide (1-) ion $\left({ }_{125} \mathrm{I}_{3}^{-}\right)$, Anal. Biochem., 331, (2004)169-176.

[12] T. Huang, L. Yang, J. Gitzen, P.T.Kissinger, M.Vreeke, A. Heller, Detection of basal acetylcholine in rat brain microdialysate, J. Chromatogr. B, 670, (1995) 323-327.

[13] T.-H. Tsai, Separation methods used in the determination of choline and acetylcholine, J. Chromatogr. B, 747, (2000)111-122.

[14] P. G. Osborne, K. Yamamoto, Disposable, enzymatically modified printed film carbon electrodes for use in the high-performance liquid chromatographic -electrochemical detection of glucose or hydrogen peroxide from immobilized enzyme reactors, J. Chromatogr. B, 707, (1998) 3-8. 
[15] Flow injection determination of choline in milk hydrolysates by an immobilized enzyme reactor coupled to a selective hydrogen peroxide amperometric sensor, $\mathrm{S}$. Pati, M. Quinto, F. Palmisano, Anal. Chim. Acta, 594, (2007) 234-239

[16] D. D. Wise, T. V. Barkhimer, P.-A. Brault, J. R. Kirchhoff, W. S. Messer Jr., R.A. Hudson, Internal standard method for the measurement of choline and acetylcholine by capillary electrophoresis with electrochemical detection, J. Chromatogr. B, 775, (2002) 49-56.

[17] A. J. Bard, L. R. Faulkner, Electrochemical Methods: Fundamental and application, 2nd ed. John Wiley\&Sons, 2001, p.736.

[18] C. A. Marquette, L.J. Blum, Luminol electrochemiluminescence-based fibre optic biosensors for flow injection analysis of glucose and lactate in natural samples, Anal. Chim. Acta, 381, (1999)1-10.

[19] B.D. Leca, A. M. Verdier, L. J. Blum, Screen-printed electrodes as disposable or reusable optical devices for luminol electrochemiluminescence, Sens. Actuators B, 74, (2001)190-193.

[20] C. A. Marquette, A. Degiuli, L. J. Blum, Electrochemiluminescent biosensors array for the concomitant detection of choline, glucose, glutamate, lactate, lysine and urate, Biosens. Bioelectronics, 19, (2003) 433-439.

[21] T. Hiroi, A. Inui, J. Jin and T. Takeuchi, Microscale electrochemiluminescence analysis with an ultrasonic vibration electrode, Microchim. Acta, 158, (2006) 269-274.

[22] R.M. Morelis, P.R. Coulet, Sensitive biosensor for choline and acetylcholine 
involving fast immobilization of a bienzyme system on a disposable membrane, Anal. Chim. Acta, 231, (1990) 27-32.

[23] F.O. Brown, J.P. Lowry, Microelectrochemical sensors for in vivo brain analysis: an investigation of procedures for modifying Pt electrodes using Nafion® , The Analyst, 128, (2003) 700-705.

[24] H. Daia, X. Wua, Y. Wanga, W. Zhoua, G. Chen, An electrochemiluminescent biosensor for vitamin $\mathrm{C}$ based on inhibition of luminol electrochemiluminescence on graphite/poly(methylmethacrylate) composite electrode, Electrochimica Acta, 53, (2008) 5113-5117.

[25] T. Hoshi, H. Saiki, S. Kuwazawa, C. Tsuchiya, Q. Chen, Anzai, J.-I., Anal. Chem.,73, (2001)5310-5315. 


\section{Figure Captions}

Fig. 1 (a) The scheme for covalently immobilization of ChOx onto the ACPG beads. (b) Schematic drawing of the enzyme reactor.

Fig. 2 Construction of the ECL flow cell. A: glassy carbon electrode $(\phi 6 \mathrm{~mm}), \mathbf{B}$ : $\mathrm{Ag} / \mathrm{AgCl}$ reference electrode, $\mathbf{C}$ : stainless steel tube, $\mathbf{D}$ : fiber optic $(\phi 1 \mathrm{~mm}), \mathbf{E}$ : quartz glass window, F: Teflon spacer $(25 \mu \mathrm{m})$.

Fig. 3 (a) Cyclic voltammograms of $50 \mu \mathrm{M}$ luminol at GC electrode in the absence (1, dashed line) and presence of $50 \mu \mathrm{M} \mathrm{H}_{2} \mathrm{O}_{2}$ (2, solid line) in $0.1 \mathrm{M}$ PBS (pH 8.5) at scan rate of $50 \mathrm{mV} / \mathrm{s}$. (b) The corresponding $I_{\text {ecl }}$-potential profile recorded during the scan. Applied voltage to PMT: $+600 \mathrm{~V}$.

Fig. 4 Effect of $\mathrm{pH}$ on $I_{\mathrm{ecl}}$. The electrolytes were (a) $50 \mu \mathrm{M}$ luminol and $50 \mu \mathrm{M} \mathrm{H}_{2} \mathrm{O}_{2}$ and (b) $50 \mu \mathrm{M}$ luminol (background), which were buffered at different $\mathrm{pH}$ values. Plot (c) is normalized ECL intensity $\left(I_{\mathrm{ecl}, \mathrm{N}}\right)$ which was the ratio of signal (a) to background (b).

Fig. 5 FIA responses to trace choline with ECL detection. Sample volume: $10 \mu \mathrm{L}$, detection potential: $+0.8 \mathrm{~V}$ vs. $\mathrm{Ag} / \mathrm{AgCl}$; carrier solution: $0.1 \mathrm{M}$ PBS containing $50 \mu \mathrm{M}$ luminol (pH 8.5); flow rate: $1.0 \mathrm{~mL} / \mathrm{min}$; voltage to PMT: +900 V. 
(a)

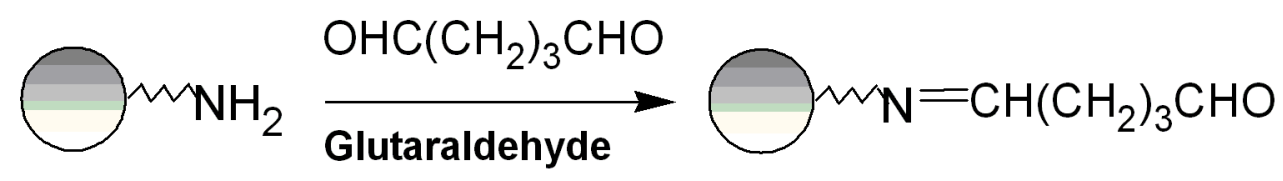

ACPG bead Stirring for $90 \mathrm{~min}$ at

room temperature

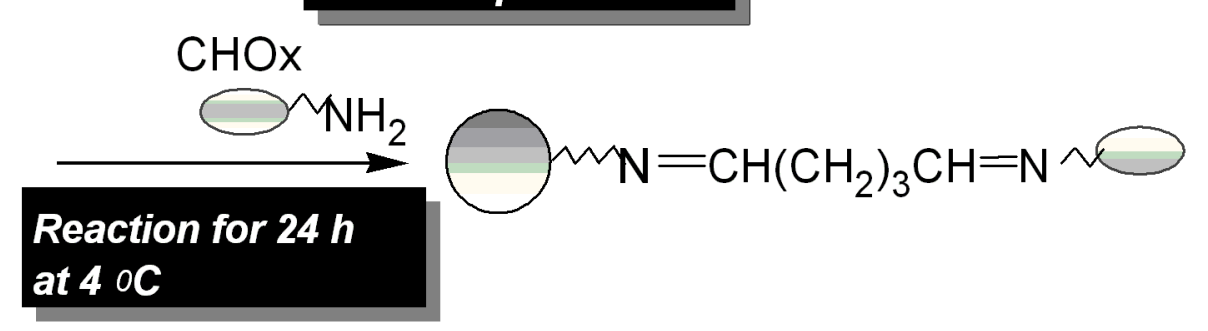

(b)

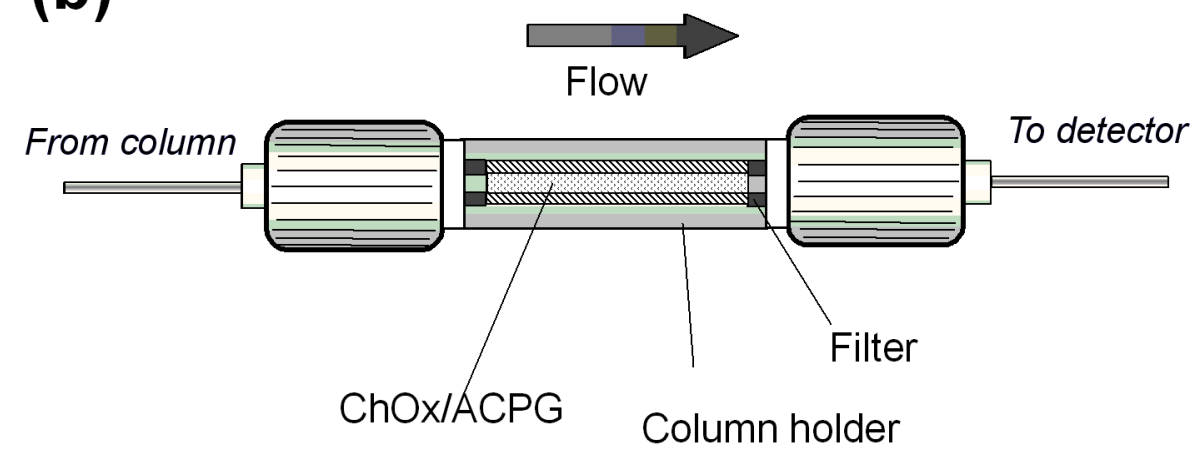

Fig. 1 


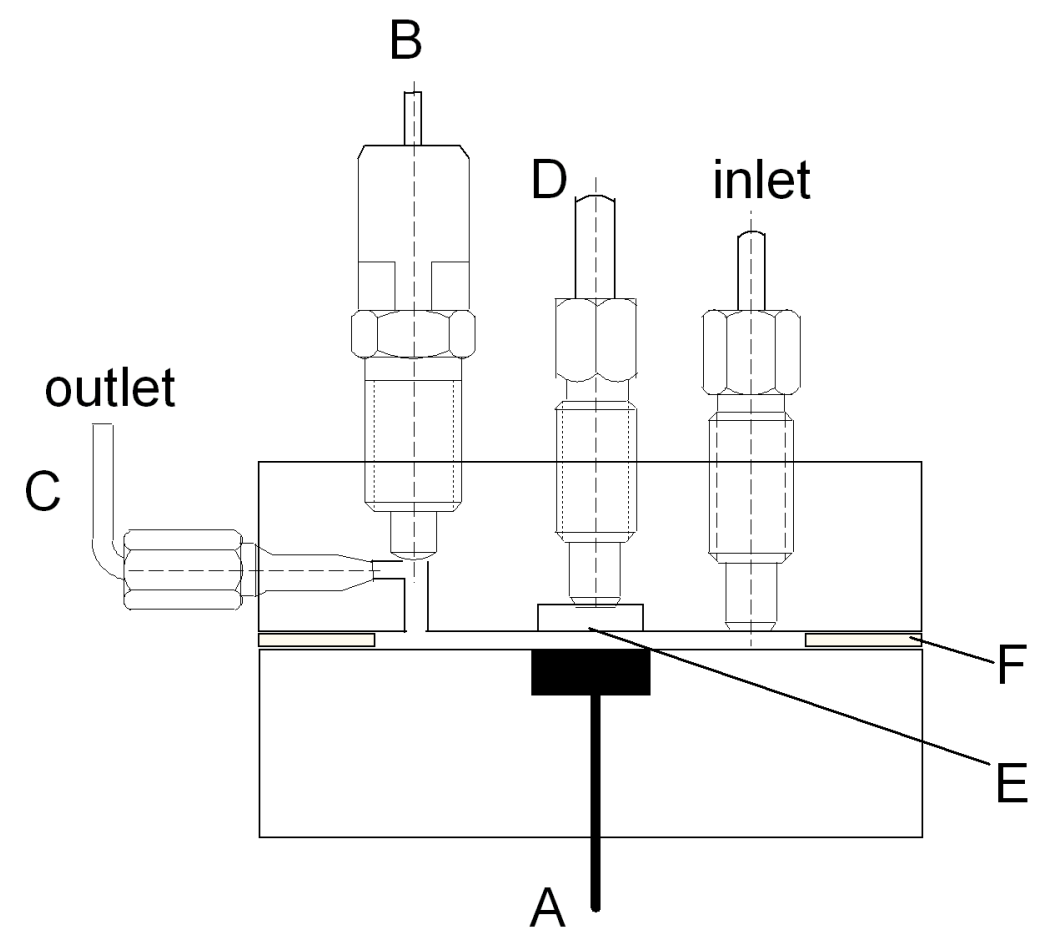

Fig. 2 


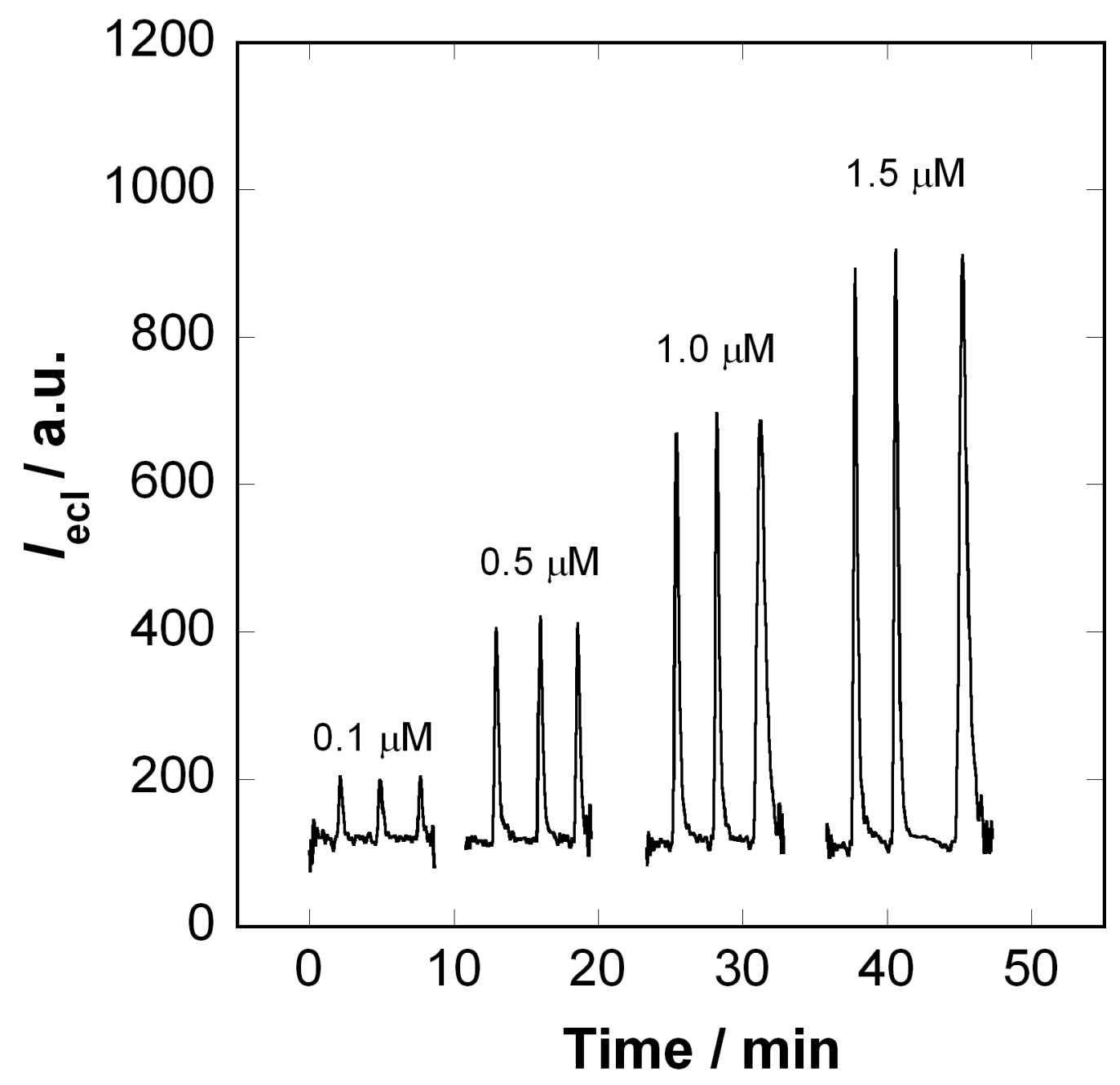

Fig. 3 


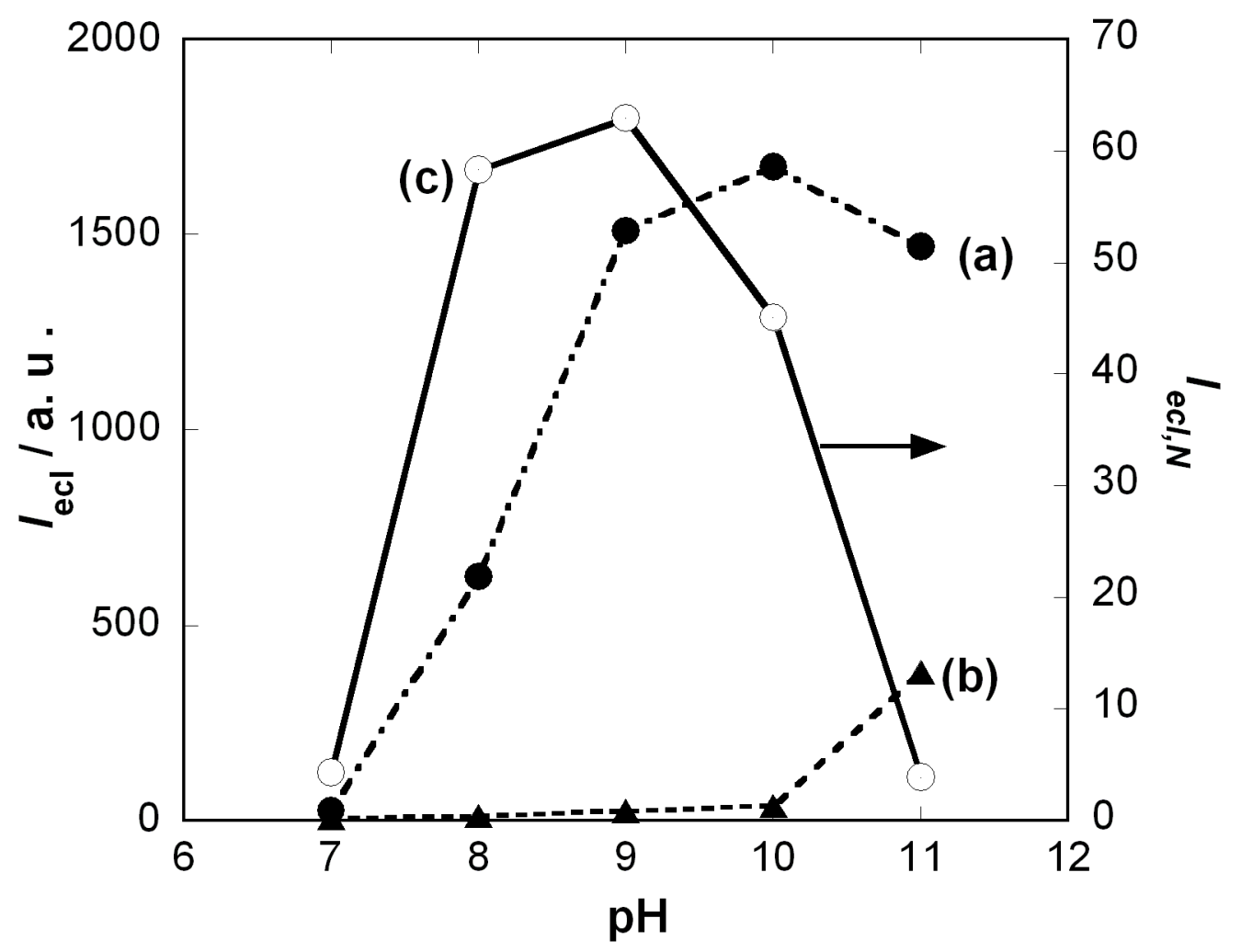

Fig. 4 


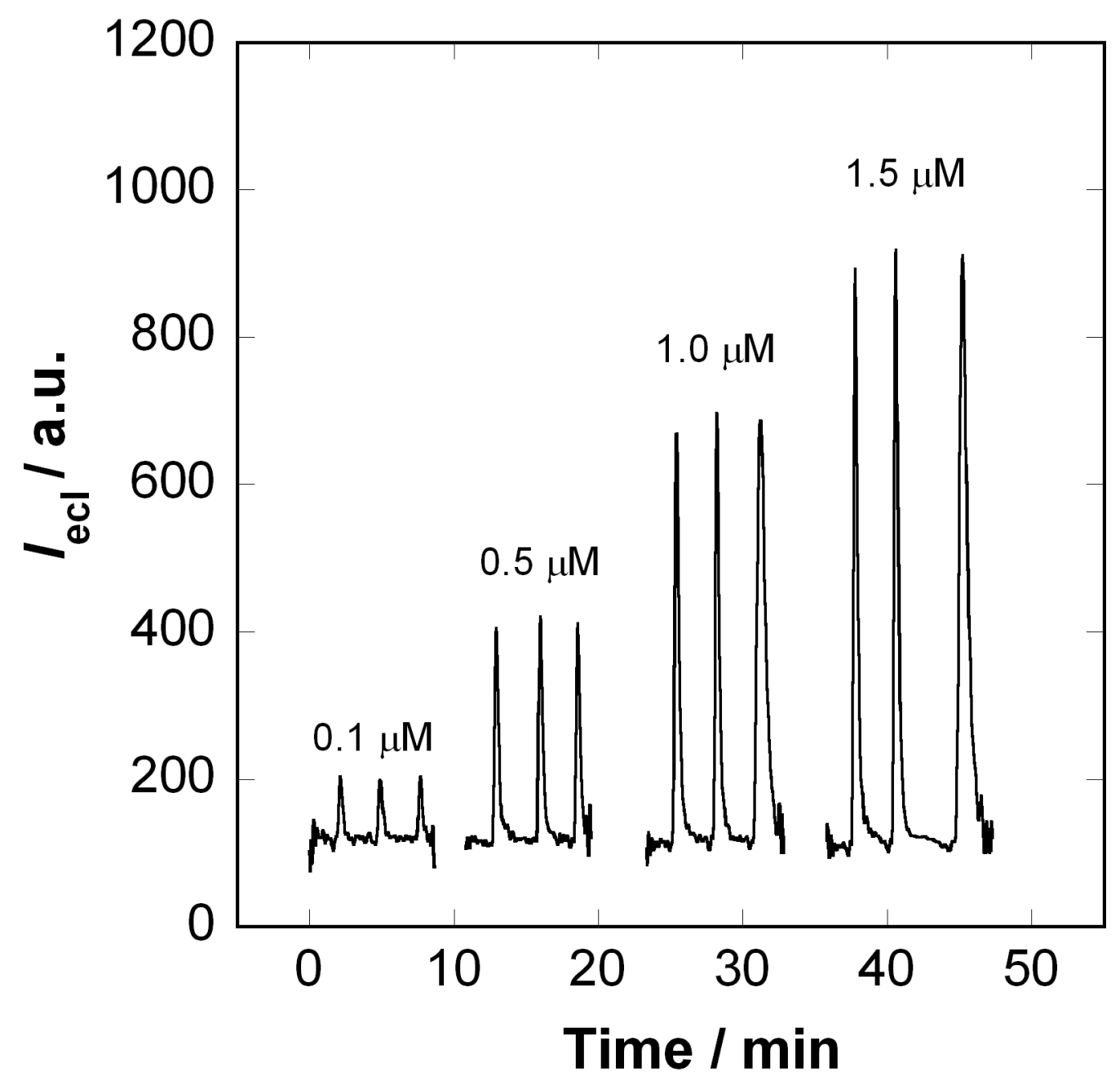

Fig. 5 


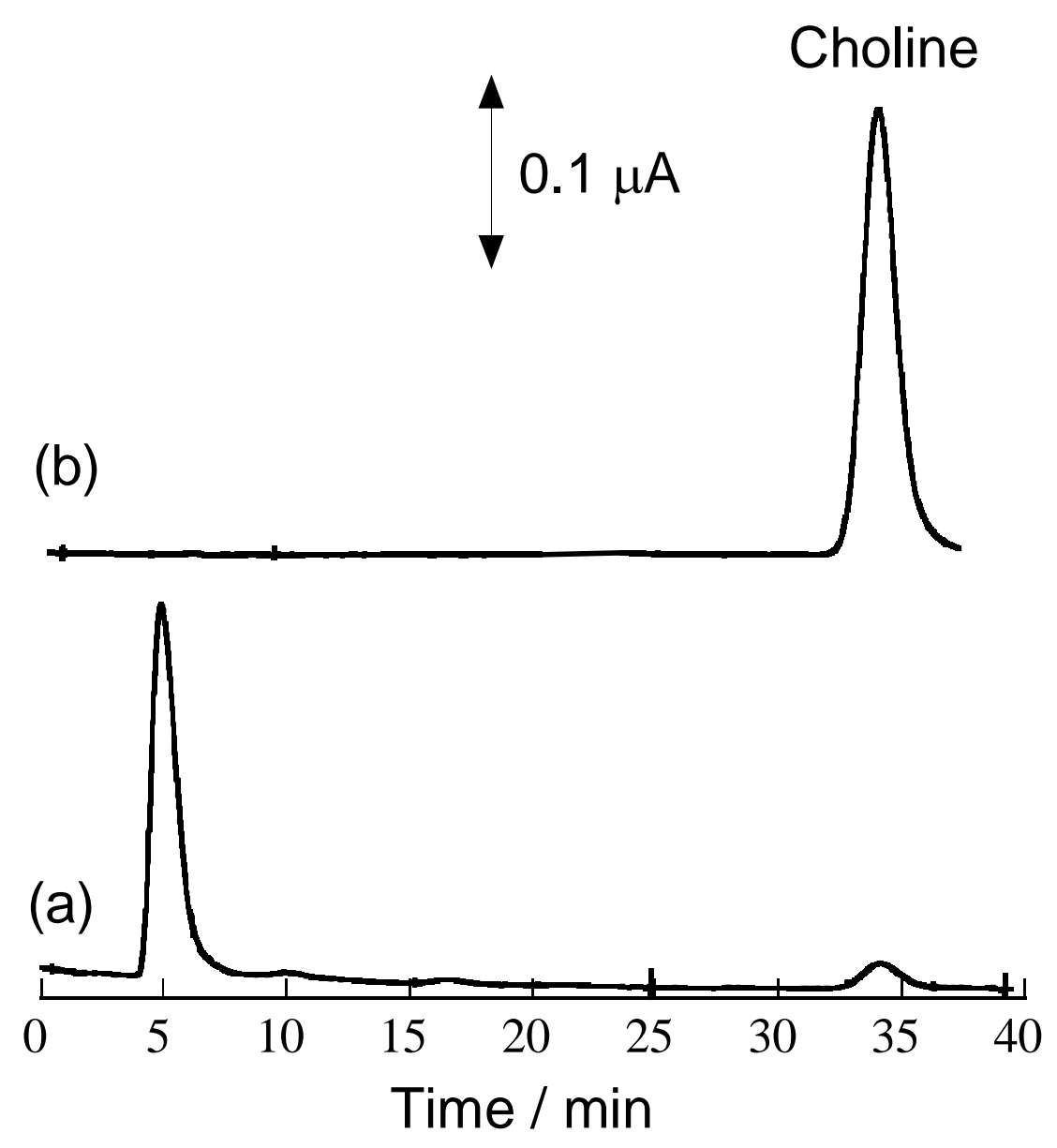

Supporting Information Fig. 6 Chromatograms of (a) human urine and (b) 50.0 $\mu \mathrm{mol} / \mathrm{L}$ of choline standard sample, respectively. The results were obtained with a microbore HPLC with immobilized enzyme reactor and amperometric detection system. The mobile phase was $0.05 \mathrm{~mol} \mathrm{~L}^{-1} \mathrm{PBS}(\mathrm{pH} \mathrm{8.5)}+50 \mu \mathrm{mol} / \mathrm{L}$ EDTA $(\mathrm{pH} 8.5)$, with a flow rate of $60 \mu \mathrm{l} / \mathrm{min}$. Sample volume: $10 \mu \mathrm{L}$; working electrode: $\mathrm{Pt}$; detection potential: $+0.65 \mathrm{~V}$ vs. $\mathrm{Ag} / \mathrm{AgCl}$. 